Canadian Journal of Higher Education Revue canadienne d'enseignement supérieur

Volume 46, No. 1, 2016, pages 121 - 137

\title{
Are University Co-operative Education Students Safe? Perceptions of Risk to Students on Work Terms
}

Rebecca Newhook

Memorial University

\begin{abstract}
As students venture off campus for university-sponsored activities, are they at risk, given that universities are better able to control risk factors on campus than they can for their off-campus activities? Co-operative education is a formalized and longstanding academic program that often sees students spend upwards of a third of their time off campus during the completion of a degree; thus, a discussion of the risks in co-operative education could provide a basis for assessing levels of risk for other off-campus activities. This qualitative, descriptive case study examines co-operative education co-ordinators' perceptions of the risks to students in co-operative education programs in Canadian universities. Fourteen co-ordinators from across Canada participated in one-on-one interviews. Co-ordinators acknowledged that of the partners in co-operative education, the student is the most at risk. However, they viewed co-operative education as a safe endeavour for students, and there was agreement that the actual risk to students is minimal. The risk factors identified by co-ordinators included personal safety, harassment, youth or limited life experience, and mental health.
\end{abstract}

\section{Résumé}

Puisque les universités contrôlent mieux les facteurs de risque des activiteurqu'elles parrainent qui ont lieu sur campus plutôt que hors campus, les étudiants sont-ils à risque lorsqu'ils s'aventurent hors campus pour de telles activités? Établi depuis longtemps, l'Éducation coopérative est un 
programme académique structuré qui voit souvent des étudiants passer plus du tiers de leur temps hors campus pendant leurs lôment. Une analyse des risques en matière d'éducation coopérative pourrait donc fournir une base d'évaluation des niveaux de risque des autres activités hors campus. Cette étude de cas à description qualitative examine les perceptions des coordonnateurs en éducation coopérative quant aux risques encourus par les étudiants des programmes d'éducation coopérative des universités canadiennes. Quatorze coordonnateurs de partout au Canada ont participé à des entrevues individuelles. Ceux-ci reconnaissent que de tous les partenaires en éducation coopérative, l'étudiant est le plus à risque. Ils considèrent toutefois l'éducation coopérative comme un effort relativement sûr pour les élèvesion, et ils s'entendent pour dire que le risque réel pour les étudiants est minime. Les facteurs de risque relevif par les coordonnateurs sont liés à la protection personnelle, au harcèlement, à la jeunesse ou au peu d'expérience de vie, et à la santé mentale.

\section{Introduction}

Universities and other postsecondary institutions are increasingly expanding their learning opportunities to include co-curricular and experiential learning opportunities, many of which take place in the community. This has resulted in questions about student safety while participating in university-sponsored activities off campus. The present research seeks to explore Canadian university co-operative education co-ordinators' perceptions of the actual and potential risks to their students and to assess their perceptions of the safety of co-operative education students. The key research question is: What do co-ordinators perceive as the main risks to students in co-operative education? This research builds upon previous explorations of co-operative education co-ordinators' perceptions of their responsibility in risk assessment and management, as well as the role of the university in preparing co-ordinators to assess and minimize risk (Newhook, 2013).

\section{Literature Review}

One of the most formal and arguably most effective forms of experiential education is co-operative education, which includes extended periods of full-time work as an integral and mandatory part of a student's academic program. The aim of a co-operative education program is to integrate theoretical classroom instruction with practical and authentic on-the-job learning in the student's area of study (Billet \& Choy, 2011, p. 25; CAFCE, 2009; Katula \& Threnhauser, 1999, p. 244; Wessels, 2005, p. 6). A recent Ipsos Reid (2010) online poll of 1,493 adult Canadians revealed that one in seven Canadians with postsecondary education participated in a co-operative education program (p. 1). It is important to note that co-operative education differs from other forms of experiential activities in that the student is both an employee and a student, so the work term is both employment and education and thus carries the legal and ethical considerations of both. Despite the growth and maturation of research about co-operative education since the early 2000 s (Zegwaard \& Coll, 2011, p. 9), there remains very little research on the legal and ethical risks involved in co-operative education in general (Newhook, 2013). 
Serious risks to students in university co-operative education programs in Canada are rare, although in three cases over the last decade, students died while on work terms. A co-op student in British Columbia died in a car accident on his way home from work following a period where he had worked 96.5 hours over the eight days prior to the accident (Workers Compensation Appeal Tribunal of British Columbia, 2009). A student from the University of Waterloo was the victim of Canada's first documented fatal wolf attack on a human (Jobin, 2007); the third-year geological engineering student was killed in November 2005 near Points North Landing, in Saskatchewan, while on a work term. In addition is the case of a University of Victoria co-op student who died by suicide in 2012, six months after he was terminated from his work term with the Government of British Columbia ("Roderick MacIsaac suicide," 2014). MacIsaac was one of seven researchers fired or suspended as part of an investigation about the misuse of personal health information; he had been unable to complete his doctorate as a result of his termination.

It is well established that universities have a duty of care to guard against reasonably foreseeable events that could result in injury for students participating in off-campus activities that form part of the student's academic program and that are supported by university staff (Birtwistle, 2002; Katter, 2002; Middlemiss, 2000, p. 79; Pearson \& Beckham, 2005; Schoepfer \& Dodds, 2010). It has also been established that co-operative education co-ordinators are uncertain about the extent of their responsibilities in assessing and minimizing risk, and that they are guided more by their own tacit knowledge and experiences than by institutional policy (Newhook, 2013). While it is clear that the university has a duty of care to protect its student on campus and in university activities off campus, the employer is also responsible for its paid employees, including work-term students. According to the Canadian Association of Co-operative Education (CAFCE), in order for a job to be eligible to be considered a work term, the conditions of employment must be full-time and paid (CAFCE, 2006, p. 2). As a result, students on work terms from most postsecondary institutions in Canada are employees and are therefore covered by their employer's insurance policies and by any legislation governing employment, compensation, and occupational health and safety.

Universities are responsible for the protection and well-being of their students, so they have myriad risk-reduction activities and policies. They are not alone in their focus on risk and risk-reduction strategies; indeed, Western societies appear to be very riskfocused, both institutionally and individually. Risk has attracted much research by contemporary sociologists. Lupton (1999) argued that society is increasingly preoccupied with notions of risk and fear as a result of intensifying feelings of uncertainty, complexity, ambivalence, and disorder, and a growing distrust of authority and the threats inherent in everyday life (pp. 11-12). Huber (2010) stated that contemporary social theorists view "the growth of risk to be the distinguishing feature of modernity" (p. 114), while Beck (1992), in his seminal publication on risk, also argued that modernity is about eradicating or minimizing exposure to risk.

This research focuses on perceptions of risk, understanding that risk is a concept constructed in reference to social, historical, and cultural conditions (Arnoldi, 2009, p. 15) and is therefore individual and subjective. Accordingly, what is perceived as risky for some individuals may be judged differently for others, based on each person's historical and cultural context. 


\section{Methodology}

The research design used a qualitative approach with descriptive case study as the methodology. The end product was a rich and thick description and account of the coordinators' perceptions and experiences of risks to students in co-operative education, illustrating the complexities of the situations as well as the similarities and differences of opinion on the subject. This research was granted full ethics clearance by Memorial University's Interdisciplinary Committee on Ethics in Human Research.

\section{Population Selection}

A criterion-based purposeful sampling technique was used with a quota or maximum variation in order to include a roughly representative subset of the population of co-ordinators. Co-ordinators from universities with long-standing co-operative education programs in multiple disciplines were invited to take part in this research. Co-ordinators from universities with co-operative education programs in only one or two disciplines or those with a co-operative education program that had been recently developed were not included, as they were not consistent with the case being studied. Colleges and other postsecondary institutions were also excluded from this study for the same reason. CAFCE assisted by sending an email to its membership, on the researcher's behalf, to introduce the research agenda and to provide legitimacy to the requests for interviews. Sixteen coordinators either self-identified or were recommended to the researcher by their director to take part. All were interviewed, yielding a participation rate of $100 \%$. It became apparent during the analysis stage that two participants were not part of the case under study, so their data were omitted from the results presented in this research. These situations are described further in the data analysis section.

\section{Data Collection Methods}

Sixteen guided semi-structured interviews were held with co-operative education co-ordinators from 10 universities across Canada. The participants represented co-ordinators from a range of co-operative education programs in a number of different disciplines, including arts, business, engineering, science, and others (not further identified, to protect the anonymity of the participants). Seven co-ordinators worked primarily in engineering and science programs; seven worked in arts, business, or other non-technical programs; and two worked exclusively with students travelling internationally for work terms. Four interviews took place over the phone, while 12 interviews were held in person. All interviews were conducted by the same researcher. The researcher used the same set of interview questions for each interview to gather background information about the co-ordinator and to explore the themes of risk in co-operative education to students, employers, the institution, and the co-ordinators themselves, as well as themes related to coordinators' understanding of risk management and institutional liability. This research paper focuses on co-ordinators' understanding of the risks to students only and does not include all of the data derived from these interviews. Interviews ranged in duration from 20 minutes to approximately one hour. All interviews were audio-recorded and subsequently transcribed. Each participant was assigned a pseudonym by the researcher. 


\section{Data Analysis}

Preliminary data analysis began during the data collection phase, although early interpretations were free-formed hunches and educated guesses. These speculations and hunches informed the next interview, and so on. An intensive analysis was completed once the data were collected, in order to construct categories and themes. The analysis was completed manually without the use of computer software. During this process, it was determined that the interview data from the two co-ordinators who worked exclusively with students travelling internationally for work terms were significantly different from those of the co-ordinators working with a variety of student work terms, primarily domestic. The focus and the work of these two co-ordinators were significantly different from the others' and were therefore considered to be outside of the case being studied; they were not part of the bounded entity of co-operative education co-ordinators and did not have a set of practices and circumstances shared with the rest of the group. For this reason, they were excluded from the analysis and their responses do not appear in the results.

\section{Results}

The majority of co-ordinators agreed that there was an increasing focus on risk, risk management, and risk awareness at their university. Some participants were able to point to specific programs or activities that had occurred or divisions that had opened within their universities in the last decade, while others were aware of a shift of consciousness only in an indirect or intuitive manner. Asked whether she thought there was an increasing focus on risk in her university, Alice said, "I think it's beginning, yeah, and that's just a vague sense," while James replied to the same question with, "I think so. I'm hearing, I'm hearing it kind of through the woodwork." Sarah and Clare both noted a shift in public consciousness and focus on risk following 9/11; Clare stated, "I think since 9/11 when we had people who were working in all parts of the world all of a sudden that day it seemed like the world was, the world changed." Neither Julia, Patricia, nor David felt there was an increasing focus on risk noticeable at their institutions.

Of the partners in co-operative education, all co-ordinators identified the student as having the greatest exposure to risk, both in terms of the types of risks they are exposed to and the significance or seriousness of the potential risks. Co-ordinators acknowledged that the student, the employer, the institution, and the co-ordinators themselves are all exposed to risk in one way or another, but that it is the student who is most vulnerable to risk in co-operative education. "Most vulnerable is the student who is out there in the workplace" (Sarah). "They [students] are the least powerful if you look at the relationship, and the most impressionable" (Tanya).

Despite co-ordinators' agreement that the student was most at risk in the co-operative education partnership, there was overall agreement that the actual risk was minimal and that, in general, students were safe on work terms. Co-ordinators were all asked to provide examples of exceptional circumstances involving students at risk on work terms, and while an assortment of examples of injuries, minor mishaps, bad experiences, and interpersonal conflicts were provided by most co-ordinators, largely they felt that these were exceptions, extremely rare cases, and did not represent the majority of work-term experiences. Susan discussed students subject to actual risk as follows: 
[W]ith respect to students over time, I guess there are more risks associated with co-op than we ever really think about. But if I've been with the university for 22 years, and if in every year I deal with 450 placements, on average, [then] that is a huge number of students [who have not experienced serious risk].

Hence, in terms of volume, while risks are present, students are in reality rarely affected.

Co-ordinators identified a number of risks to the student, which are discussed in the following sections.

\section{Personal Safety}

Personal safety on work terms was identified by virtually all co-ordinators as a potential risk to students. In fact, when asked what they thought was the most significant risk in co-operative education, 10 of the 14 (71.4\%) co-ordinators interviewed felt student personal safety was the most significant risk.

Not unexpectedly, awareness of and focus on workplace health and safety for co-operative education students was higher among the co-ordinators of engineering and science programs, where student work-term positions are typically riskier as they may include laboratory, manufacturing, construction, and other onsite work. "In working in manufacturing environments, or if they happen to go offshore, or up North in a camp, then there could be actual safety risks for them" (Susan). "In engineering in particular, they are often times exposed to big, moving machinery, so there certainly is safety issues around that" (Alice). "They're going to face, especially where we have engineering students, there's going to be health and safety issues" (Patricia). "Laboratory safety is a big one, so the safety of the student, physical safety" (James). Natalie qualified her concern, stating:

In terms of the physical risks to students, I don't, from my experience so far, I haven't identified too many. Now granted, we have science students, obviously, that go out to work in labs. So I guess there is some modicum of possible physical risk, but they all take laboratory safety courses and that sort of thing.

While she acknowledged the risk, she described it as a "modicum of possible physical risk," noting that she felt the actual risk to be extremely low. This sentiment was widespread among the co-ordinators who were interviewed.

Generally, co-ordinators felt that between the university and the employer, students received adequate health and safety training. "It is the responsibility of the employer to train these students in terms of safety, [and] I am getting feedback on what kind of safety training the students are undergoing, which I'm fine with" (Rachel).

Several co-ordinators supplied examples of occasions when students had suffered minor injuries or broken bones as a result of a work term, but these represented a handful of injured students out of thousands of work terms. Two examples of extreme situations did arise in the discussions with co-ordinators; however, they are not presented here, in order to protect the anonymity and confidentiality of the participants.

\section{Harassment}

The vast majority of co-ordinators indicated that they perceived harassment to be a potential risk to co-operative education students on work terms. Harassment in the con- 
text of the discussions with co-ordinators included bullying, physical or emotional intimidation, neglect, and sexual harassment. David explained that students "face the same risk as any worker-there's the risk of being harassed, sexually harassed, a risk of being bullied by colleagues and employers." Similarly, Amanda said, "[A]nything could happen to them when they're in the workplace ... they might be subject to bullying or discrimination or something like that in the workplace, sexual harassment."

Clare viewed harassment differently and drew the connection between workplace harassment and mental health (discussed in more detail in a later section):

I can think of abuse, and not probably the most outward abuse, but abuse of getting them [students] to do the stuff no one else wants to do, which is a risk, I guess, to people's confidence, it's a psychological risk probably to be given really bad work all the time.

Similarly, Sarah expressed that harassment was a broad concept: "I think harassment can happen at so many different levels. If a supervisor is not giving enough guidance and then criticizing [the student]." She elaborated and provided this scenario:

It could be bullying, there are some instances that I can think of ... the student could see paperweights flying out of the little cubicle because the supervisor was mad, so how do you think the student feels walking in there and asking any questions?

Susan tempered her concern, noting that it was very uncommon for students to be sexually harassed in her experience: "[T] here's very few cases of that come past my desk. Very few. Probably one or two cases of sexual harassment, in all the years I've been there." Patricia noted concern for female co-operative education students working in non-traditional occupations and work sites, who are particularly vulnerable to sexual harassment: "where it's engineering and we would have lots of cases where we have females students at work in a very male-dominated environment, so that's a concern of ours."

Approximately half of the co-ordinators I interviewed were able to provide specific examples of students being harassed by colleagues or supervisors on work terms. David spoke of a small, family-owned business that mistreated a group of five co-op students, who all quit en masse one day, which as a result prompted David to be more diligent in vetting the suitability of small-business employers for co-op students. James noted an example of students being physically intimidated on a work term:

They were male students, and they felt intimidated physically by their foreman. They didn't feel like they could say anything because they were afraid of him. And this one person, one young man, was more sensitive than the rest, and I would say he has likely some degree of mental health issue, and he didn't handle it well, and he came in [to the co-op office] on a regular basis, we had many phone calls, he was very upset by it, very affected by it.

It was clear that student harassment on work terms was taken seriously by co-ordinators, often with long-term consequences, such as in the situation Julia outlined that resulted in the termination of the co-operative education partnership between the university and the employer: 
I would say [the supervisor was] a bit of a bully, frankly, so the student definitely was experiencing that, and it was just a really, a lot of back and forth with her and the employer and then finally realizing that after this work term, we're not going to be posting with this employer again.

Tanya also explained being aware of a student who felt harassed by her work-term supervisor: "I did know of another student who was working up North . . . who was feeling harassed by a supervisor. ... I met with her afterwards, and she seemed fine."

One of Sarah's students endured harassment on her work term: "[T]he supervisor of the female student, he was singing something, a song that had her name in it, an actual song, some song, I don't know what, so I think that made her very uncomfortable.” Julia provided an example of sexual harassment and the supporting and mediating role of the co-operative education co-ordinator:

A student on their last, second last day of their work term was out for the staff party and someone made a comment about her physical [appearance], and she came in after her work term really upset about it and I could, it was very impactful for her because she didn't know how to, if she should say anything, what she should do, and really it was kind of a sexual harassment issue, it was, so I was immediately on the phone with the fair-treatment advisor because she was, she's a student but she was also an employee of that environment, and she's an adult too, so we had to try to, really what I did and what I was advised to do, was lay out all the options for her and then she, at the end of the day because she had the information, was able to make the choice that was best for her.

This example highlights the complicated relationship between the co-operative education co-ordinator, the student, the employer, and the university.

One example of a student perceiving discrimination based on sexuality surfaced in my discussions with co-ordinators. Natalie explained:

The camaraderie between the people who work there and sort of the things that they would say to each other were quite homophobic but were considered ok. And this particular student was very, very hesitant to sort of bring up his concerns because he didn't want to create any waves. And he said, "It's fine, but it makes me very uncomfortable."

\section{Youth and Limited Life Experience}

The co-ordinators involved in this research work primarily with undergraduate students, who are typically in their late teens and early twenties, the occasional mature student notwithstanding. As a result of their students' age, co-ordinators noted that many co-operative education students lack life experience and, sometimes, maturity. Clare remarked on the vulnerability of the co-op student as a young worker:

As young workers, they're more vulnerable anyway and as new to a company or industry, you're always vulnerable. ... But put that with someone who is naïve, new to workplaces anyway and then it's a workplace that they don't know much about, and the vulnerability quotient just goes right up. 
Alice remarked on her students' sometimes poor decision-making skills resulting from their youth and inexperience, noting her heightened feelings of responsibility for her students: "generally speaking, I probably keep my eyes open more than I should because I know that they are young adults and still not always making good decisions."

Nancy also acknowledged that she perceived her students to be at risk as a result of their youth and lack of life experience:

[A student] doesn't have a lot of life experience and it's one thing for us to say they're adults, but you know, we all gathered our life experience as we went, and I think all of us create that. Our life experience when we were nineteen is a whole lot different than it is now. You know? And so I think on the student perspective that there are risks related to the fact they don't have a lot of life experience.

Tanya argued that life experience and maturity had a direct impact on work performance and therefore could impact a student's success on a work term and in the subsequent work-term evaluation: "[T] he extent to which a student is, let's say, mature, has had some sort of independence, responsibility in their lives pre taking on co-op, impacts greatly their performance on the job."

It is widely argued that the current generation of young people are generally less independent, live more sheltered lives, and have parents who are more attentive and involved in their children's lives than they were in the past. Julia elaborated:

Generally, millennials have had very involved parents, and if they've lived at home their whole lives and then they move away for the first time [for a work term], that involvement, it's really, now you need to figure out how to get to work on time and what to wear and how to get your groceries and all those things that if you've lived at home you probably take for granted.

There was general agreement among co-ordinators that one of the main goals of cooperative education programs is to address this lack of experience by supporting and nurturing students' exposure to new environments, new tasks, and new people, thereby increasing life experience and maturity levels. Tanya expressed the role of the co-operative education co-ordinator in this process as follows: "[M]aybe because of the nature of who we're dealing with-these are young people, they're in their formative years-we can have an impact on their lives, and we're aware of it."

Co-ordinators clearly acknowledged that co-operative education students are typically young and need guidance and support through new experiences in order to get the maximum benefit from their co-operative education experiences. Consequently, co-ordinators largely perceived student inexperience to be a risk in co-operative education, but they were aware of their crucial role in mitigating against and limiting their students' exposure to this risk.

\section{Mental Health}

Student mental health was identified by virtually all co-ordinators as a risk in cooperative education. Co-ordinators noted four main areas of concern related to student mental health, including: serious mental illness, the loneliness or homesickness factor, self-confidence/self-worth, and stress. 
Susan noted particular concern for student mental health; when asked what she considered to be the most significant risk in co-operative education, she responded that student mental health was the most significant risk, in her view. Similarly, David spoke of his concern for student mental health or emotional well-being in general. In answer to the same question, he responded that personal safety was the most significant risk but that "second to that would be the emotional risk;-we try to avoid putting students in situations that we might know are, from an emotional point of view, are going to be disturbing or distracting, harmful."

Like many co-ordinators, David mentioned that his department works very closely with the counselling unit at his university, and while he is very aware of mental health and the risks that mental illness can pose, he does not consider this part of his role as a coordinator: "[W]e work quite closely with our counselling department ... so if it comes up, we refer them to counselling. It's not our work role, but we're all pretty aware." Natalie also spoke of her unit's partnership with mental health services available at her university: "[T]here's really been a push university wide for all faculty and staff to go through mental health training."

Nancy explained how, in her view, mental illness can compromise a student's success in selecting an appropriate work term as well as that individual's performance on a work term:

Their mental health can be a risk to co-op in the sense if they're not very, if they're not mentally stable and settled within themselves, then again, they may go to a job, they might misjudge the job they want, they might go to one that's too much pressure, too busy, doesn't work, they're already, maybe not that stable. And so, yeah, then their mental health can be a risk.

Tanya also drew a link between mental health and work performance: "[T]he extent to which your mental health is in good shape impacts directly your success on the job, there's no question."

Several co-ordinators cited incidents of students not being able to complete work terms as a result of a serious mental health problem. Susan stated she had been involved in a number of situations related to student mental health, and she provided an example of a student who had had a psychotic break on a work term:

I've had a student, years ago, who called me at home, who had been out on her first work term, first couple of days of work and basically she, as it turned out, she was having a psychotic break. So in that instance, she didn't finish her work term. ... We went and got her and brought her to where she had to be to be taken care of. So that was a huge risk for her, and she was at a very vulnerable stage in her life. And this extra added stressor of going to work just put her over the edge.

Susan reiterated the connection between mental illness and students' age: “[T]he age that they're at is such a vulnerable age, and ... their mental illness is going to come up then, if they have a predisposition for it. And the stress could certainly bring it on." James talked about an incident with a suicidal student on a work term:

I once had a student who was suicidal. I didn't even know it until somebody from our ... counselling unit notified me. I didn't realize it. I knew he was having performance problems, but we, he actually ended up being fired from the job. 
Alice had also experienced a student having to leave a work term as a result of a serious mental illness. Here she drew the potential connection between workplace safety and mental health:

I know that students have had to leave work because of mental health issues. So it was probably a good thing that they had to leave work before something happened to somebody else or to them. And I don't mean the student was going to physically harm someone else, but if they're going through troubles in their life and they're not paying attention, then the consequences can be disastrous if you're working in a dangerous worksite.

Similarly, Natalie and Patricia had worked with students who had had to terminate work terms prematurely as a result of a serious mental illness: "[W]e have actually had students leave work terms partway through because of mental health issues" (Patricia).

Susan also identified students travelling outside of their home city or province as being more vulnerable to mental illness:

When students go away to work, [that] in itself can be a huge stressor for students, and we as co-op co-ordinators would never really know how well someone is, if they are well enough to go away, and the individual themselves might not be selfaware enough to know that they aren't well enough to go.

She reinforced the idea that students travelling away from home for work terms are especially vulnerable to mental health illnesses: "[T]he risk is if they go away and get really sad and once again it can easily bring out the mental illness." Clare also discussed the risks for students travelling away from home for a work term and identified loneliness and homesickness as potentially risky for student mental health: "I think that's a risk, because when students are away from home for the first time, they're facing new jobs, new people ... and I think that there is a loneliness risk and a psychological risk there." She elaborated on her concerns about loneliness:

They're thinking this is going to be such a great thing, living in this great big city, and what they realize is that they're lonely. They're surrounded by millions of people, and it's lonely. So I often think about that as being a big risk for students.

Sarah also reiterated this concern: "I'm not sure how to categorize it. When students leave town and go away, it opens up all kinds of other risks." She elaborated on her thoughts about the loneliness factor: "[W] hen you're away from home, you're a lot more vulnerable to maybe loneliness, who knows, whatever your situation, a bad thing, it gets aggravated when you're alone, your safety [net] is not there."

Several co-ordinators communicated their perceptions of the connection between student mental health and co-operative education in terms of self-confidence and self-worth. "It also poses a risk to their confidence levels as well because they're put into a situation that they're not really prepared for and they're not kind of being guided through in some cases" (Alice). Julia discussed the lasting effects of a work term on a student's confidence level: 
I've seen students who had a really bad work term and frankly probably a bit of a mean supervisor, and that impacts their confidence going into the next work term. It's almost like the next two work terms, they're trying to rebuild what was lost in the first.

Julia went on to talk about confidence and experiences of failure in co-operative education. She explained how the competitive set-up of co-operative education in terms of the interview and job-offer process is the first opportunity for many students to experience failure in a meaningful and important way:

Co-op is for many students the first time they've ever failed. Ever. Or, you know, really competed where there's a bottom line, so you might have competed in soccer and everybody gets a medal or a certificate, but at the end of the day, there's only one spot and only one job, so you might think or you've been told your whole life that you're going to do whatever you want to do, and the workplace is finally telling you that that might not be the reality.

Julia elaborated on the competitive nature of co-operative education and students' notions of self-worth: "[Y]ou're competing against your friends, and you really at some point can question whether you're worth it if it's not working out for you." Nancy also noted the potentially profound effect that a negative experience on a work term can have on a student's self-image:

Just as anything in life, when they go out on co-op [work term] with certain expectations and images of themselves and they don't find that they are what they thought they were, that's a mental health issue there. Suddenly, how they see themselves has changed drastically, and that can have profound effects on them.

Co-ordinators acknowledged that co-operative education is a stressful endeavour. University students face many stressors, but co-operative education students face many added stressors. They have to participate in additional activities, including professional development seminars, limiting the time they can commit to other pursuits. Co-operative education students are also expected to apply for multiple jobs and attend subsequent interviews, all of which requires a great deal of time and energy in order to achieve success, as well as being stressful activities in themselves. Several co-ordinators remarked on the extra work completed by co-operative education students compared to other university students. "It's like taking another course when you're on your academic terms" (Julia).

Susan suggested that the extra stress experienced by co-operative education students could bring out a mental health problem in students with a predisposition to mental illness. Julia noted that the number of student situations related to stress, anxiety, and mental health seemed to be rising: "I've noticed in the six years that I've been here that students have, there have been more issues with students levels of stress and anxiety and mental health since I started working here." She went on to say that being at university "is a stressful time. And ultimately, co-op is super stressful." She noted that co-ordinators at her university routinely deal with students who are extremely upset and stressed: "I mean, we joke sort of, like, oh, first crier of the semester, and that sounds pretty cynical, but it kind of speaks to the level of stress that the students are experiencing." 


\section{Discussion}

The primary research question in this study asked: What do co-ordinators perceive as the main risks to students in co-operative education? Largely, the co-ordinators believed that co-operative education was a safe endeavour and that examples of extreme situations were very rare. The majority of co-ordinators also agreed that there was an increasing focus on risk at their institution. Whether real or imagined, their responses support the notion of society's elevated risk consciousness and fear of the unknown. Co-ordinators' awareness of risk is in line with many academics' assertions that the concept of risk is pervasive in everyday life in most Western societies (Tulloch \& Lupton, 2003).

Without exception, co-ordinators indicated that students were the most at-risk population in co-operative education. Many reasoned that this was a direct result of co-operative education students' age, limited experience, and lowly place in the hierarchical world of work. Clearly co-operative students are adults, but according to Côté and Bynner (2008), "one of the least contested issues in contemporary youth studies is that the transition to adulthood is now taking longer on average than in the past, delayed until the mid-twenties to late-twenties for a significant proportion of youth cohorts in many developed societies" (p. 253). Therefore, it can be argued that most undergraduate university students are transitioning to adulthood but do not yet have the established commitments and independent lifestyles that most older people associate with being an adult. As a result, the majority of the students participating in co-operative education are still in a transitional stage of life, neither child nor adult. Nelson and Barry (2005) summarized much research on this period of human development, which has found that emerging adults are more likely to engage in risk-taking behaviours in general. The transition to adulthood is, for many, a time of exploration and experimentation, testing and trying, taking risks. It is not surprising, then, that co-ordinators identify the student as the most at-risk and that they identify youth as one of their students' key risk factors. Indeed, co-operative education is perfectly positioned to capitalize on the risk-taking behaviour of the emerging adults enrolled in these programs; co-operative education encourages risk-taking by facilitating both career and academic exploration and experimentation in a supportive and safe environment. Co-ordinators acknowledged that their students' youth and limited life experience put them at risk, even while those same qualities encouraged risk-taking through seeking varied and new work experiences.

Other risks to the students relate to their personal safety at work, workplace harassment, and mental health. The ramifications of workplace health and safety violations and workplace harassment are well known, but less well known is the vulnerability of university students to mental health problems. Storrie, Ahern, and Tuckett (2010) conducted a systematic review of academic publications on university student mental health, which demonstrated that serious mental illness in student populations was a growing problem worldwide. According to their review, common problems experienced by university students included depression, eating disorders, self-harm, and obsessive compulsive disorder (p. 2); Martin (2010) identified depression and anxiety as the main conditions (p. 264).

While mental health problems affect people of all ages, three-quarters of people who will develop mental illnesses do so between the ages of 16 and 25 (Martin, 2010, p. 259), which is typically the time of life when people attend postsecondary education. An Ameri- 
can study of students who experienced psychiatric problems during college showed that just under half of the students (49\%) experienced the onset of mental illness while they were attending college (Megivern, Pellerito, \& Mowbray, 2003, p. 221); roughly half of the students experienced psychiatric problems only after entering postsecondary studies. While the findings of Martin and of Megivern et al. showed that postsecondary students experienced high levels of mental health challenges, Stallman (2010) went further and demonstrated that university students experienced significantly higher rates of mental health problems than the general population. She concluded that the "extremely high prevalence of mental health problems in university students provides evidence for this being an at-risk population" (p. 249). Thus, co-ordinators correctly identified co-operative education students as being at risk for mental health problems.

In general, there was no correlation between the academic discipline of the students and the risks to students that the co-ordinators identified. Co-ordinators in engineering and science programs demonstrated greater awareness of and focus on personal safety, although virtually all co-ordinators identified personal safety as a risk, regardless of the discipline. Otherwise, the risks identified were not related to the discipline; rather, coordinators from different disciplines perceived the risks to apply to their students equally.

\section{Conclusion}

The unique element of co-operative education when compared to other kinds of offcampus university-sponsored activity is that the work term student is a paid employee of the host organization. While it is clear that the university has a duty of care to cooperative education students on work terms, it is also clear that employers have responsibilities to their employees, co-operative education students included. It has already been established that co-operative education co-ordinators are unclear where the boundaries of their responsibilities lie when compared with those of the other players in co-operative education (Newhook, 2013), perhaps because the university and the employer could both be held legitimately responsible, given the dual nature of the co-operative education student as both student and employee.

Co-operative education is categorized as a safe activity by those who work most closely with co-operative education university students; however, co-ordinators acknowledge that there are possible risks to the student. Co-ordinators are well-placed to take the lead in reducing the level of risk to students on work terms by educating students about the possible risks as well as developing practices to help students and employers talk to each other about safety at work.

On campus, co-ordinators can develop programs and/or information packages for students to make them aware of the possible risks. For example, co-ordinators routinely include professional development seminars for students as part of the preparation offered to students before they go on a work term. Co-ordinators can elaborate on topics such as workplace safety, harassment, conflict management, ethics, and workplace behaviour to educate students on best practices for safe and professional behaviour. Although it is quite difficult to make up for the youth and limited life experience of the students, thorough discussions and education on these topics would be of great benefit. In addition, offices are available on all university campuses to deal with instances of harassment, and there are services available to students needing counselling and mental health care, which 
were also identified as risk factors for co-operative education students. Students need to be aware that these services are available to them while they are on work terms as well as when they are on campus.

Co-ordinators have the opportunity to influence student safety and well-being off campus as well. In developing jobs and speaking with employers, co-ordinators can ensure that employers are aware of the goals of co-operative education in providing developing professionals with a safe and supportive environment in which to learn, apply theoretical classroom knowledge, and explore career options. Co-ordinators can also establish procedures to ensure that employers and students are talking to each other directly about workplace safety, harassment, and policies and procedures, by developing forms or checklists that must be completed by the employer and student when the student starts work.

The risks identified in this research apply directly to co-operative education students; however, comparison with students participating in other off-campus university-sponsored activities can be made. It is therefore also important that other university faculty and staff who work with students involved in other off-campus activities take note of these risks and identify solutions and policies to ensure student safety off campus, particularly where there is not a partnering agency that is also responsible for the student's safety. While the solutions and policies for other student off-campus activities must be developed specifically for the realities of each program and situation, practices employed in co-operative education programs may be applicable.

\section{Acknowledgments}

I would like to extend my thanks to the participants of this study. This research was supported in part through funding received from the Canadian Association for Cooperative Education.

\section{References}

Arnoldi, J. (2009). Risk: An introduction. Cambridge, UK: Polity Press.

Beck, U. (1992). Risk society: Toward a new modernity. London, UK: Sage.

Bell, S. (2013, October 28). "Waterloo Suresh" gets two years prison for helping terrorists acquire "sophisticated" military tech. National Post. Retrieved from http:// news.nationalpost.com/2013/10/28/suresh-sriskandarajah-who-pleaded-guilty-toterrorism-is-a-role-model-ndp-mp-writes/

Billett, S., \& Choy, S. (2011). Cooperative and work-integrated education as a pedagogy for lifelong learning. In R. K. Coll \& K. E. Zegwaard (Eds.), International handbook for cooperative and work-integrated education (pp. 25-30). Lowell, MA: World Association for Cooperative Education.

Birtwistle, T. (2002). Liability and risk assessment in student activity abroad-the UKCOSA survey. Education and the Law, 14(4), 231-252.

Canadian Association for Co-operative Education [CAFCE]. (2006). CAFCE accreditation standards and rationale. Retrieved from http://www.cafce.ca/_Library/ Bylaws/Standards_Rationales.pdf 
Canadian Association for Co-operative Education [CAFCE]. (2009). Benefits of cooperative education. Retrieved from http://www.cafce.ca/about-us-benefits.html

Côté, J., \& Bynner, J. M. (2008). Changes in the transition to adulthood in the UK and Canada: The role of structure and agency in emerging adulthood. Journal of Youth Studies, 11(3), 251-268.

Huber, M. (2010). The emergence of academic risks in British higher education. In B. M. Hutter (Ed.), Anticipating risks and organising risk regulation (pp. 113-139). New York, NY: Cambridge University Press.

Ipsos Reid. (2010, January 20). Canadian post-secondary education: Impact of coop education programs. Special mini-report. Retrieved from http://www.cafce.ca/_ Library/_documents/ResearchIpsos2010.pdf

Jobin, B. (2007, November 2). Wolves killed student: Jury. Prince Albert Daily Herald. Retrieved from http://www.paherald.sk.ca/Education/2007-11-02/article-178031/ Wolves-killed-student-jury/1

Katter, N. A. (2002). Negligence in the delivery of higher education: How vulnerable are our universities? Journal of Educational Administration, 40(4), 390-399.

Katula, R. A., \& Threnhauser, E. (1999). Experiential education in the undergraduate curriculum. Communication Education, 48(3), 238-255.

Lupton, D. (1999). Risk. Florence, KY: Routledge.

Martin, J. M. (2010). Stigma and student mental health in higher education. Higher Education Research \& Development, 29(3), 259-274.

Megivern, D., Pellerito, C., \& Mowbray, C. (2003). Barriers to higher education for individuals with psychiatric disabilities. Psychiatric Rehabilitation Journal, 26(3), 217-231.

Middlemiss, S. (2000). Legal liability of universities for students. Education and the Law, 12(2), 69-91.

Nelson, L. J., \& Barry, C. M. (2005). Distinguishing features of emerging adulthood: The role of self-classification as an adult. Journal of Adolescent Research, 2O(2), 242-262.

Newhook, R. (2013). Perceptions of risk in co-operative education. Journal of Cooperative Education and Internships, 47(1), 78-93.

Pearson, D. R., \& Beckham, J. C. (2005). Negligent liability issues involving colleges and students: Balancing the risks and benefits of expanded programs and heightened supervision. Journal of Student Affairs Research and Practice, 42(4), 460-477.

Roderick MacIsaac suicide: B.C. government apologizes to researcher's family. (2014, October 3). CBC News British Columbia. Retrieved from http://www.cbc.ca/news/ canada/british-columbia/roderick-macisaac-suicide-b-c-government-apologizes-toresearcher-s-family- 1.2787048

Schoepfer, K. L., \& Dodds, M. (2010). Internships in sports management curriculum: Should legal implications of experiential learning result in the elimination of the sport management internship? Marquette Sports Law Review, 21(1), 183-201. 
Stallman, H. (2010). Psychological distress in university students: A comparison with general population data. Australian Psychologist, 45(4), 249-257.

Storrie, K., Ahern, K., \& Tuckett, A. (2010). A systematic review: Students with mental health problems a growing problem. International Journal of Nursing Practice, 16(1), 1-6.

Tulloch, J., \& Lupton, D. (2003). Risk and everyday life. London: Sage.

Workers Compensation Appeal Tribunal of British Columbia. (2009). Decision Number: WCAT-2009-01504. Retrieved from http://www.wcat.bc.ca/research/ decisions/pdf/2009/06/2009-01504.pdf

Wessels, M. (2005). Experiential learning. Lansdowne, South Africa: Juta \& Co.

Zegwaard, K. E., and Coll, R. K. (2011). Exploring some current issues for cooperative education. Journal of Cooperative Education and Internships, 45(2), 8-15.

\section{Contact Information}

Rebecca Newhook

Memorial University of Newfoundland

Faculty of Arts and Faculty of Science

rnewhook@mun.ca

Rebecca Newhook is an academic staff member in co-operative education with the Faculty of Arts and the Faculty of Science at Memorial University of Newfoundland. Rebecca holds a Bachelor of Arts and a Master of Education. She is the Co-chair of the CAFCE Atlantic Research Committee, a member of the CAFCE Research Committee, and the 2012 recipient of the CAFCE Research Award for her research on perceptions of risk in cooperative education. She lives in St. John's with her partner and their two daughters. 